\title{
ENTRE TEATRO E LITERATURA: UMA EXPERIÊNCIA SOCIAL E AFETIVA EM MOACYR SCLIAR
}

\author{
BETWEEN THEATER AND LITERATURE: A SOCIAL \\ AND AFFECTIVE EXPERIENCE IN MOACYR SCLIAR
}

\author{
Silvânia Maria da Silva Amorim Cruz* \\ Luzia Cristina Magalhães Medeiros ${ }^{* *}$
}

\begin{abstract}
Resumo: O objetivo do artigo é provocar reflexões sobre a obra $O$ irmão que veio de longe de Moacyr Scliar (2006), mediante o exercício dramático, potencialmente capaz de auxiliar na formação do leitor infantil. Essa obra emociona ao conduzir o leitor pela voz do menino Cauê, um pequeno índio orgulhoso de sua origem, no entanto, Cauê enfrenta a mudança para a cidade grande, lidando com o mais cruel dos sentimentos: o preconceito. Scliar envereda a história para a descoberta dos laços que prendem afetivamente, seja uma família, seja uma sociedade, levando os leitores a caminhos de luta contra a intolerância. Compartilharemos questões que foram despertadas por meio da leitura e da atividade dramática para compreensão e fruição desse texto literário.
\end{abstract}

Palavras-chave: Formação do leitor. Exercício dramático. Literatura infantil.

Abstract: The purpose of the article is to provoke reflections on the work The brother who came from far from Moacyr Scliar (2006), through the dramatic exercise, potentially able to assist in the formation of the children's reader. This work thrilled to lead the reader through the voice of the boy Cauê, a small Indian proud of its origin. Cauê faces the change to the big city dealing with the cruelest of feelings: prejudice. Scliar turns history into the discovery of the ties that bind affectively, be it a family or a society, leading readers to fight against intolerance. We will share questions that have been awakened through reading and dramatic activity to understand and enjoy this literary text.

Keywords: Reader training. Dramatic exercise. Children's literature.

\section{Introdução}

\author{
"A viagem prossegue e embarcamos no faz-de-conta, onde \\ nos encontramos com a imaginação, com a imitação e com a \\ criação. Fomos majorando caminhos, estação a estação. Mudamos \\ trajetos, trocamos as malas, mas os sonhos sempre estavam ali \\ presentes, cena a cena..." (DAL COLETO, 2007, p.58).
}

As crianças brincam espontaneamente de jogos de faz de conta e a partir da brincadeira de imaginar, elas apropriam-se do mundo que as cerca. Ao representar vontades, alegrias, tristezas, sonhos, enfim, ao ter essa necessidade de encenar sentimentos, o teatro torna-se uma arte representativa da nossa cultura.

Por esse caminho, o presente artigo pretende demonstrar que a atividade de mediação entre a literatura infantil e o teatro favorece vivências de leituras mais significativas, uma vez que a dramatização do texto literário conduz a criança leitora à

\footnotetext{
* Mestrado Profissional em Língua Portuguesa. Universidade de Pernambuco - Garanhuns. Professora de Língua Portuguesa no Ensino Fundamental e Médio da rede estadual de Pernambuco. Tutora EAD do curso de Especialização em Gestão e Coordenação em Educação pela Universidade de Pernambuco. professorasilvania@hotmail.com

${ }_{* *}$ Mestrado Profissional em Língua Portuguesa Universidade de Pernambuco - Garanhuns. Bolsista CAPES. Desenvolve pesquisa acadêmica na área de Letramentos e Linguagens com linha de produção em Leitura e Produção textual: Diversidade social e Práticas Docentes. cristinamedeiros13@ hotmail.com
} 
expressão de seus sentimentos. O teatro empresta a voz dos personagens às crianças, envolvendo-as com toda beleza imaginativa que emana da leitura literária.

Dentre os ganhos desse fazer dramático para sentir o texto, destacamos a expressão da oralidade. Por essa via aberta, o professor pode motivar as crianças à liberdade verbal, pois, através do teatro, desenvolvem-se segmentos expressivos (corporal, facial e oral/verbal) importantes enquanto habilidades sociais contextualizadas. Para tanto, fundamentamos esse trabalho em Colomer $(2003,2007)$ quanto à leitura na literatura infantil e Cosson (2014) quanto à atividade literária em sala de aula.

Ao longo do artigo, defenderemos a literatura infantil necessariamente poéticoliterária e não utilitária, ou seja, ligada à ficção, à intenção estética, à especulação existencial e à criatividade, em oposição a uma literatura infantil ligada apenas à lição e à intenção pedagógica.

Em razão disso, escolhemos a sequência básica proposta por Cosson (2009), que resultou no desenvolvimento da oralidade, da expressão corporal, da impostação da voz, como também motivou o entrosamento com o outro, a criatividade, a vivência emocional e, consequentemente, a leitura literária.

O livro O irmão que veio de longe de Moacyr Scliar (2006), foi indispensável a essa viagem literária citada em nossa epígrafe, com uma narrativa comovida e envolvente, traz à luz de nossa consciência questões sobre diferenças culturais, preconceito e, principalmente, sobre afeto e tolerância. A escolha dessa obra para a realização de oficinas de leitura com alunos do $4^{\circ}$ ano deve-se à crença de que, por ela, tem-se o poder de seduzir e de despertar a vontade de realizar outras viagens pelo mundo dos livros, pois trata de questões do dia a dia como amizade, convivência e família.

Esse poder surge, conforme Garcia (2007, p. 51), quando desfrutamos do texto como um "[...] sedutor, como um animal caçador, fica à espreita, esperando a aproximação de um leitor. E, fisga-o. E o leva para dentro de seu universo, enredando-o nas palavras, nas ideias, nos buracos da significação, na ausência e presença de ideias...”.

\section{A literatura na infância e os caminhos da leitura em Moacyr Scliar}

Motivar a leitura da literatura na infância é fazer romper sementes. Toda criança cria um universo imaginário fértil à capacidade inventiva das palavras, em razão disso, o ato de ler livros nesta fase é germinativo e a tendência é frutificar para novas leituras. Assim, incentivar o ato de ler livros tão cedo desperta para a necessidade de conhecer um pouco desse universo literário infantil.

Embora existam muitas discussões em torno do conceito da literatura infantil, como bem expressa os questionamentos de Drummond, quando diz sobre ser a criança um ser à parte, reclamando uma literatura também à parte, muitos teóricos buscaram conhecer melhor esse campo nas últimas décadas. Dentre eles, Coelho (2000) a define assim:

Literatura infantil é, antes de tudo, literatura; ou melhor, a arte: fenômeno de criatividade que representa o mundo, o homem, a vida, através da palavra. Funde os sonhos e a vida prática, o imaginário e o real, os ideais e sua possível/impossível realização... (COELHO, 2000, p. 9) 
Em razão desse "poder" da literatura, sabemos que o contato com o multifacetado universo dos livros, na infância, movimenta a fantasia durante os exercícios de recriação imaginativa, além da afetividade e da integração da criança enquanto sujeito social.

Os livros para crianças e jovens apareceram como fenômeno cultural específico no século XVIII, sua função era formar moralmente a criança leitora por meio de fábulas e outras narrativas sobre bons sentimentos e heroísmo. De acordo com estudos de Colomer (2003), muitos elementos constituem um repertório de qualidade dos livros escritos para crianças, ou daqueles que elas gostam de ler, geralmente característicos da presença do folclore e da literatura oral, da ficção fantástica e, mais modernamente, do humor, do jogo literário, da narrativa psicológica, da incorporação de recursos visuais e da quebra de tabus temáticos.

As produções infantis contemporâneas refletem as crescentes mudanças nessa área, principalmente por tratarem do desenvolvimento do comportamento leitor. Dessa forma, a reivindicação da literatura infantil e juvenil, na escola, serve de fomento a uma educação literária desde os anos iniciais, mas a literatura não deve conduzi-las, unicamente, às intenções educativas e formativas. Soares (1999) argumenta que mais vale pensar na literatura que interessa às crianças do que a literatura destinada às crianças, geralmente esta última excede em didatismos.

Para não tropeçar nos entraves pedagógicos e potencializar o efeito da leitura em âmbito escolar, podemos contar com produções literárias brasileiras de boa qualidade, autores como Marina Colasanti, Lygia Bojunga Nunes, Roger Mello, Laura Ingalls Wilder, Ricardo Azevedo, J. K. Rowling, Manoel de Barros, Ruth Rocha entre outros, revelam uma ampla variedade de temas e estilos. Neste trabalho, mostramos, como aporte de qualidade, a produção literária de Moacyr Jaime Scliar (1937-2011) contista, romancista, ensaísta e cronista - caracterizada pela crítica como uma narrativa de autoconsciência, marcante pela heterogeneidade de temas.

Estimulado por sua mãe professora, Scliar apegou-se desde cedo a Alexandre Dumas e Lewis Carroll, povoou sua infância dos personagens de Lobato e Érico Veríssimo, para mais tarde mostrar outras terras da imaginação em seus escritos. Somente depois de 1981, após outras produções destinadas ao público adulto, Scliar adentra, ruidosamente, o campo da literatura para crianças com as novelas Cavalos $e$ Obeliscos (1981) e A Festa no Castelo (1982). Zilbermam (2011) afirma que nas primeiras obras desse autor predominam a ação e o bom humor, a valorização da vida familiar, o respeito por professores e, sobretudo, a criação de personagens com as quais jovens leitores podem se identificar. A respeito de sua obra Zilbermam acrescenta:

Para Scliar, a literatura para crianças e jovens era tão importante quanto às narrativas encaminhadas para adultos. Desse modo, aquelas podem ser valorizadas, de uma parte, por sua qualidade própria e, de outro, por se constituírem em uma estação de passagem para o conjunto da obra de um dos mais estimados escritores brasileiros do fim do século XX. (ZILBERMAM, 2011)

Tanto fez neste universo literário que essa autora classifica a obra infantil de Moacyr Scliar em três grupos: narrativas para adolescentes, com personagens jovens e idealistas que sonham transformar o mundo; narrativas para crianças, como $O$ Tio Que Flutuava, Uma História Só pra Mim, O Irmão Que Veio de Longe e Aquele Estranho Colega, o Meu Pai, nesse grupo, as personagens se caracterizam por necessidades interiores que se transformam em problemas, até serem solucionados. 
O terceiro grupo de obras consiste em adaptações de clássicos da literatura brasileira, nestas produções intenciona motivar o leitor, de preferência jovem, a buscar as obras originais. Assim, Câmera na Mão, O Guarani no Coração atualiza o romance indianista de José de Alencar, $O$ Mistério da Casa Verde retoma a matéria de $O$ Alienista, novela de Machado de Assis, Ciumento de Carteirinha absorve o tema central de Dom Casmurro, e $O$ Sertão Vai Virar Mar, conforme sugere seu título, dialoga com Os Sertões, de Euclides da Cunha.

Caracterizar a literatura infanto-juvenil de Scliar é como olhar um menino no interior do homem, o próprio autor diz:

Quando escrevo, não posso deixar de pensar, com melancólica ternura, no menino que escrevia suas historinhas em papel de embrulho, no menino que sempre acreditou na magia da ficção. A este menino que fui e a todos os meninos (e meninas) dedico todos os meus livros (SCLIAR, 2007, p.56).

Nas narrativas infantis de Scliar, percebemos que a criança vive no limiar entre as angústias da moderna sociedade e a fantasia, sendo que a condução equilibrada do enredo, à beira destes caminhos, leva a criança a ter a crença no poder transformador do bem, sem isso, possivelmente, não haveria esperança em ser adulto, uma vez que a realidade vai podando o espírito curioso e criativo da criança. Ler a literatura de Scliar é acordar para dentro, onde ainda se vive o melhor do ser humano.

Sobre sua dedicação à arte literária para a juventude, Scliar afirma:

[...] continuo pensando no jovem escritor que fui. E é por isso que gosto de escrever para gente jovem; a juventude é a fase da vida em que um livro pode mudar a cabeça da gente. Livros fizeram a minha cabeça. Espero que os meus façam a cabeça de meus leitores (SCLIAR, 2007, p.112).

A exemplo de Scliar, podemos confirmar que leitores se formam com livros, numa conversa secreta ou compartilhada, o leitor criança escamoteia o mundo de suas personagens e atravessa seus caminhos. Nessa aventura de ler, a escola é e deve continuar a ser, mesmo correndo os riscos de escoar a essência verdadeira da leitura literária, um espaço dilatador para este exercício.

\section{0 exercício teatral e os caminhos da formação de leitores na infância}

No intento de mediar à leitura da obra de Scliar, de forma que as crianças sintam-se aguçar o sabor dessa literatura, faz-se importante ao mediador pensar sobre o processo da leitura e os caminhos da formação do leitor, bem como os modos de ler e compartilhar.

Embora a obra de Scliar escolhida para este trabalho não ofereça grandes obstáculos à compreensão dos leitores com idade aproximada entre 9 e 12 anos, é preciso considerar que o percurso da narrativa pode levá-los para além do tecido no texto, a outras pontes de conhecimento. Por isso, entendemos que além de possibilitar o acesso a livros, formar leitores implica também em desenvolver sua capacidade interpretativa. Nesta mesma linha, Prado (2007, p. 20) afirma que 
A possibilidade de permitir que o leitor descubra esse poder que vem dos livros deve ser interpretada pelo mediador como um desafio constante, pois formar bons leitores significa, antes de mais nada, encantar, seduzir, despertar a vontade de mergulhar em muitos "mares de histórias", de conhecer muitas outras portas de entrada para o mundo das letras e dos livros que levem ao autoconhecimento e a uma dimensão do outro que até então se desconhecia.

Nesse mergulho em "mares de histórias", as crianças podem deslocar-se por diferentes mundos e assumir papéis sociais diversos. A leitura realiza-se nessa interação leitor/autor/texto com fins da produção de sentidos, por isso o mediador pode motivar o diálogo com a obra e permitir ao leitor acionar conhecimentos de mundo e construir a teia de significados compartilhados. Acreditamos, a partir dessa visão, que a leitura, mesmo sendo individual, é uma atividade social. Assim afirma Cosson:

O bom leitor, portanto, é aquele que agencia com os textos os sentidos do mundo, compreendendo que a leitura é um concerto de muitas vozes e nunca um monólogo. Por isso, o ato físico de ler pode até ser solitário, mas nunca deixa de ser solidário. (COSSON, 2014, p. 27)

Desse modo, a leitura promove idas e vindas ao mundo do eu e do outro. Consciência adentro, percorre-se o universo das linguagens pelas vias do texto. Nessa empreita, entender como se forma um leitor nessa ligação mundo/eu/outro que se converge no texto não é tarefa simples e superar os desafios de ir a leituras progressivamente mais complexas tem conduzido professores e mediadores de leitura a pensarem maneiras de auxiliar o leitor jovem a ampliar sua capacidade de compreensão.

Entre as várias estratégias para acionar os mecanismos de interpretação do texto, os jogos dramáticos são uma prática eficiente, geralmente consistem na encenação da narrativa ou na simulação de cenas criadas a partir dela. Propicia aos leitores momentos de grande interação com o texto e com eles mesmos e "requer a integração de várias linguagens artísticas e vem daí sua importância para a formação de leitores" (COSSON, 2014, p.110).

A dramatização, como estratégia de interpretação, permite a externalização e internalização da leitura, também através de recursos como a oralidade e a gestualidade em que são expressos o tom indignado ou aprovador, o riso ou as expressões de tristeza. Além disso, ao emprestar sua voz à personagem, o leitor pode compreender e até julgar as ações desta personagem na obra, identificando-se ou não com ele.

O recurso da dramatização da obra germina uma grande interação com o texto e entre os próprios leitores, o "experenciar" e o "compartilhar" são potencialmente vivenciados nesse recurso que torna a leitura uma vivência tridimensional. De acordo com Cosson (2014, p. 111), o que deve interessar não é o espetáculo em si, mas como os alunos constroem a dramatização da obra, "como experienciam o texto para transformá-lo em ação dramática". Essa tradução incide na interpretação.

Também outras vantagens educativas ficam evidentes no recurso da dramatização, embora esta pesquisa não se detenha a analisá-las, é importante ressaltálas, como memorização, concentração, sociabilidade, autoexpressão e impostação da voz, e ainda como condição de sensibilizar e vencer a timidez e a baixa autoestima. Também várias técnicas de jogos dramáticos podem ser usadas, Albuquerque (2007) cita algumas formas de promovê-las para fortalecer a leitura literária: jogo de personificação- RPG, quadro vivo - tableaux, cadeira-depoimento- hot seating entre 
outros; essas podem ser técnicas eficazes para auxiliar o leitor a interpretar a obra e permitirem observar os avanços e percalços desse processo.

Assim, o leitor porta-se de forma ativa na construção das impressões de leitura e em diálogo com a comunidade escolar. Colomer compreende que

para a escola, as atividades compartilhadas são as que melhor respondem a esse antigo objetivo de 'formar o gosto' a que aludimos; porque comparar a leitura individual com a realizada por outros é o instrumento por excelência para construir o itinerário entre a recepção individual das obras e sua valorização social. (COLOMER, 2007, p. 73)

Vale considerar também que o leitor ao submergir no discurso literário encontra-se como sujeito no exercício da imaginação, também ali "tem possibilidade de avaliação dos valores postos em sociedade", ali "desafia os discursos prontos da realidade" (COSSON, 2014, p. 50). Nesse sentido, a dramatização garante oportunidades de (des) construção de valores.

\section{$4 O$ irmão que veio de longe: compartilhando o caminho da leitura}

O livro O irmão que veio de longe (2006) foi a obra de Scliar escolhida para a realização deste exercício. Esta narrativa de Scliar emociona ao conduzir o leitor pela voz do menino Cauê, que conta como a chegada do meio-irmão índio preenche a alma de sua família arrasada pela morte prematura do pai, um indigenista dedicado ao trabalho em aldeias da Amazônia. O pequeno indiozinho, orgulhoso de sua origem, enfrenta a mudança de vida da aldeia próxima ao Vale do Javari, na Amazônia, para uma cidade no sul do país, lidando com o mais cruel dos sentimentos, o preconceito. Ao saber deste filho de seu marido, caso que acontecera antes de seu casamento, a mãe, D. Carmen, e os filhos recebem Carlinhos, que sofrera já muitas perdas com a morte da mãe no parto e, recentemente, do pai e da senhora com quem vivia. Apesar do sentimento de tristeza, a história enfatiza como Carlinhos tornou-se querido pela sua nova família e como suas tradições e crenças continuaram fazendo parte de quem ele era, sendo algumas vezes amado ou rejeitado por isso.

Scliar envereda a história para a descoberta dos laços que prendem afetivamente, seja uma família, seja uma sociedade, levando os leitores a caminhos já conhecidos de luta contra a intolerância. Ao final da trama, Carlinhos consegue, graças ao conhecimento da natureza, encontrar sua irmã e o irmão de Renato, garoto que mais o atormentava com preconceitos. Com isso, o ódio cedeu lugar à gratidão.

Para melhor descobrir os tantos diálogos possíveis e consolidar a proposta de mediação de leitura com a obra de Scliar, foi realizada uma sequência básica de leitura conforme o modelo apresentado por Cosson. Nesse modelo, construímos um itinerário de exploração do texto em etapas que sistematizam a atividade da leitura e dão início ao letramento literário.

O letramento literário é conceituado como um "processo ativo de apropriação da literatura enquanto construção literária de sentidos", desse modo, "o letramento literário configura a existência de um repertório textual, a posse de habilidades de trabalho linguístico-formal, o conhecimento de estratégias de construção de texto e de mundo que permitem a emersão do imaginário no campo simbólico" (PAULINO e COSSON, 2009, p. 67). 
Daí a concepção de letramento, atrelada à literatura, funciona para ampliar a forma de ver o texto não apenas como produto do universo da palavra, mas como forma de vivência e interpretação desse universo. Cosson (2014, p.12) esclarece que "o processo de letramento que se faz via textos literários compreende não apenas uma dimensão diferenciada do uso social da escrita, mas também, e, sobretudo, uma forma de assegurar seu efetivo domínio".

A sequência básica de Cosson envolve quatro etapas. A primeira delas é a motivação, atividade que consiste na construção de uma situação na qual se pode estabelecer um laço estreito com o texto que se vai ler a seguir, sempre com o cuidado de não tirar o foco do texto ou conduzir a interpretação do leitor.

A segunda etapa é a introdução, nessa etapa, o mediador dedica-se à apresentação da obra. Cosson alerta que a maneira como a obra é introduzida pode interferir na recepção desta obra. Explicitar os pressupostos da seleção, as razões pessoais e metodológicas, dá a impressão de liberdade de leitura diante de obras que são previamente selecionadas para leitura pelo mediador. Os aspectos físicos da obra (a capa com suas cores, imagens, título; orelha e outros elementos paratextuais) fazem parte do processo de leitura.

A terceira etapa é a leitura propriamente dita, Cosson (2014, p.64) salienta a importância de intervalos, pois constituem atividades específicas orientadas pelo mediador para saber o andamento da leitura, as dificuldades específicas dos alunos e intervir de forma eficiente. Funcionam como um "diagnóstico da etapa da decifração", ajudando o mediador a perceber problemas, como o desinteresse em continuar, o ritmo da leitura e problemas ligados ao vocabulário. Em casos de textos mais longos, podem vir a servir para sumarização, recapitulação e síntese.

Cosson, ao propor os intervalos, também sugere que outros textos menores, que tenham uma ligação com o texto maior, sejam intercalados como forma de tecer aproximações breves, ou ainda ser feita uma microanálise estilística de recursos expressivos, no entanto, salienta alguns cuidados. Os intervalos são programados com a turma e devem ter um tempo curto para não se perder o foco da leitura.

$\mathrm{Na}$ quarta etapa do método de letramento literário, a interpretação, dois momentos são considerados: um interior, de caráter individual, em que se tem a apreensão da ideia global do texto, e outro exterior, que trata do compartilhar e ampliar os sentidos coletivamente. Nesse momento, enquadra-se bem a dramatização, as crianças podem verbalizar as emoções que o texto provocou além de ser um exercício que podem utilizar da criatividade sem interferências do mediador.

A avaliação também é um momento a ser planejado, tanto durante o processo para que subsista em seu propósito de ação mediadora entre os meios e os fins, como também, ao término da atividade para "fornecer aos participantes uma visão geral dos resultados alcançados" (COSSON, 2014, p.112). Nos modelos de sequência propostos por Cosson, a avaliação ocorre durante os intervalos de leitura, como também nos registros da interpretação ao final da leitura.

A sequência básica para leitura do livro $O$ irmão que veio de longe, no $4^{\circ}$ ano, foi planejada da seguinte forma:

- A motivação (1h/a): produção de painel no formato de uma casa. Neste espaço, as crianças devem colar os desenhos que fizerem de suas famílias e apresentá-las ao grupo, será possível que as crianças observem que há outras famílias que se constituem de formas diferentes. 
- A introdução (20min): apresenta-se o livro $O$ irmão que veio de longe, autor, ilustrador, ano de edição, dialogando sobre o título e as possibilidades de significação da ilustração da capa.

- A leitura: em voz alta, feita pelo mediador, com intervalo ao término do terceiro e sexto capítulos para atividade que consiste em diálogo para levantamento de hipóteses ou constatações, sumarização e exibição de vídeos sobre a cultura indígena (dança, música e lendas, relacionadas às partes mencionadas no texto).

- A interpretação: produção de cenas dramatizadas de partes da narrativa; será feita por grupos diferentes, com a presença de um narrador para cada grupo, e ao término da leitura, para fins de motivar o diálogo com o texto. Essa atividade servirá também de avaliação para entender quais foram os avanços, em razão disso, as próprias crianças produzirão os diálogos e decidirão sobre o uso do espaço e do figurino, conforme as cenas solicitadas: $\left(1^{\circ}\right.$ grupo: Visita de Geraldo à casa de D. Carmem e a notícia dada aos irmãos Peri, Cauê e Jaci; $2^{\circ}$ grupo: Carlinhos canta e conta lendas de seu povo na escola; $3^{\circ}$ grupo: Carlinhos briga por causa de preconceitos no caminho de casa e Poti o defende; $4^{\circ}$ grupo: família de Carlinhos o apoia em momento difícil de solidão; $5^{\circ}$ grupo: Carlinhos ajuda a salvar a irmã do colega preconceituoso).

\section{Reflexões sobre o trajeto literário: outros caminhos da leitura}

A escola campus, onde foi realizada a sequência de leitura literária, conta com 300 alunos matriculados no Ensino Fundamental I, está localizada num bairro periférico da cidade de São José do Belmonte- PE. Apesar de ter sido ampliada nos últimos dois anos, a referida escola não conta com biblioteca nem sala de leitura, os professores têm pouco acesso a livros também.

De acordo com relatos de alunos, goteja-se livros literários na sala de aula, uma vez que a caixa de livros é levada para sala duas vezes ao mês. A leitura, geralmente, acontece de forma silenciosa e, com menos frequência, compartilham-se as impressões em diálogos mediados pelo professor.

A proposta de leitura e dramatização feita à turma de 29 crianças do $4^{\circ}$ ano agradou, mas preocupava a professora que relatou ser um período pouco apropriado pela proximidade da semana de concluir avaliações bimestrais. Entraves pedagógicos à parte, realizamos a sequência em uma semana.

O primeiro momento da motivação emocionou, pois cada criança colava no painel/casa o desenho da família, comentando como era formada. Problemas recentes de divórcio, afastamento de familiares e de alcoolismo desbotaram alguns sorrisos enquanto montava-se aquele painel.

Em seguida, houve a introdução com informações prévias e físicas da obra. $\mathrm{O}$ que chamou a atenção foram as hipóteses levantadas pela leitura da imagem na capa, uma das crianças sugestionou não se tratar de irmão "de verdade" já que o menino que estava de costas era muito diferente dos outros que o olhavam. A expressão "irmão de verdade" gerou outros comentários interessantes.

O mediador chamou a atenção para a moldura da imagem e sua semelhança com a moldura de um espelho, no entanto, o silêncio sobre aquela interpretação alertou para as limitações da compreensão metafórica, considerou-se melhor para o mediador não intervir e deixar para comentar ao término da leitura. 
Figura 1: capa do livro O irmão que veio de longe, ed. 1, 2002.

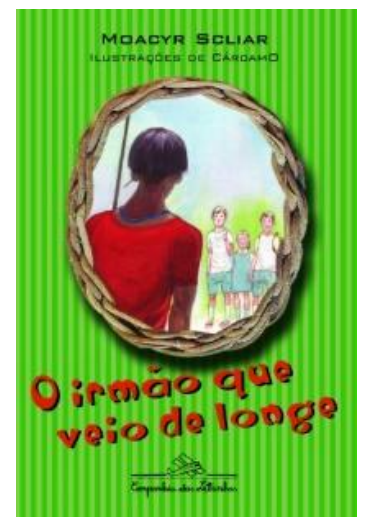

Fonte: Página do Grupo Companhia das Letras ${ }^{1}$

Seguiu-se a leitura em voz alta pelo mediador, durante o primeiro intervalo da leitura, ao concluir o terceiro capítulo, seguiu-se o diálogo, apresentando em slides imagens de aldeias do Vale do Javari, na Amazônia, e do trabalho de indigenistas nessas aldeias. Alguns trechos da obra foram retomados, como o da página 37, em que Carlinhos cita conhecer o livro de José de Alencar, $O$ guarani. Aproveitou-se o momento para desfazer estereótipos sobre indígenas e mostrar a importância de pais que motivam a leitura em casa.

Embora não fosse possível ter livros para todas as crianças acompanharem a leitura, e sabendo da importância deste suporte, a leitura do quarto, quinto e sexto capítulos foi realizada individualmente e em silêncio, através de cópias xerografadas do livro. Esse momento foi necessário para perceber avanços e dificuldades de leitura e compreensão do texto. Alguns terminaram em aproximadamente 15 minutos enquanto outros debulhavam devagarinho as páginas da história. A espera gerou impaciência nas crianças que leram mais rapidamente e certa ansiedade em comentar a narrativa lida, uma dizia "eu vou esquecer se demorar muito". No entanto, o mediador pediu que fizessem um desenho de uma cena da parte lida enquanto aguardavam alguns colegas concluírem a leitura.

Ao término do sexto capítulo, o diálogo aflorou as contextualizações, principalmente em relação à atitude preconceituosa de Renato, um colega de sala que não gostava de Carlinhos, e ao fato de terem sido espalhadas na escola a frase carimbada "faça como a varíola - acabe com o índio". A encenação da discussão de Renato e Poti, foi realizada para demonstrar como Scliar encaminhou a narrativa: o sentimento fraterno entre Carlinhos e Poti, que inicialmente não existia, estava tão presente que Poti não se questionara em defendê-lo das ofensas de Renato. Conversas sobre bullying encerraram o dia, mas o término da sequência de leitura continuaria no próximo encontro.

Após ouvir algumas hipóteses sobre o fim da narrativa, o mediador, o professor e uma aluna fizeram uma leitura coletiva em voz alta dos capítulos finais. A atividade que se seguiu para efeito de compreensão da obra e expressão da criatividade foi dividir a turma em grupos e sortearam-se cenas importantes da narrativa para dramatização. Cada grupo articulou as falas e a movimentação sem grandes dificuldades, o mediador apenas contribuiu com a organização da sala e com a integração dos membros da equipe.

\footnotetext{
${ }^{1}$ Disponível em <https://www.companhiadasletras.com.br/detalhe.php?codigo=40270> Acesso em maio de 2018.
} 
As cenas dramatizadas dinamizaram o ato de ler e cativaram o interesse das crianças pela obra. Foi possível perceber que compreenderam a narrativa, no entanto, foram além dela ao expressarem em suas falas uma reprovação "agressiva" a Renato, menino que tratara mal o índio Carlinhos. Talvez como uma manifestação espontânea despertada pela leitura.

Outro aspecto interessante observado foi a cena dramatizada em que Carlinhos conta a lenda do uirapuru e a lenda de Jaci, nome dado a sua irmã. O talento do aluno/ator para contador de histórias despertou a plateia de alunos que interagiam na cena e pediam "conta outra". Esse aluno, relata a professora, "é novato na turma, sempre muito quieto e calado", a oportunidade de dramatizar permitiu que se integrasse melhor com a turma. Possivelmente, Scliar pela sensibilidade de bom escritor, fizera de Carlinhos, também novato, um contador de histórias.

$\mathrm{Na}$ última cena dramatizada, foi solicitado à equipe que criasse uma cena mostrando o que acontece depois do fim da narrativa de Scliar. Para surpresa da turma, as crianças imaginaram que a nova família de Carlinhos visitaria a Amazônia, para conhecer outras lendas indígenas. Uma aluna sugeriu que todos os outros levantassem os braços para simular as árvores da floresta amazônica. Esse novo final, além de outras coisas, mostrou o fascínio pelas histórias fantasiosas e direcionou a outros possíveis itinerários de leitura. Um novo livro foi logo apresentado, aproveitando o momento motivador das crianças.

Um texto tece outro e este, mais outros, como um galo tecendo a manhã, outra explicação não seria melhor do que essa, de João Cabral de Melo Neto, para mostrar como de um livro pode-se ir a outros, e assim, germinarem-se leitores.

\section{Considerações finais}

O contato com histórias, lidas e encenadas, possibilita às crianças, a partir das suas experiências pessoais, construir sentidos acerca do mundo e delas mesmas, pois os pontos de vista são modificados, assim como o agir sobre a realidade.

Nesta proposta, buscamos oportunidades da criança vivenciar, de forma lúdica e interativa, o gosto que Scliar compartilha em seus livros: o de ler e imaginar. Concordamos com Paulo Freire (2007, p.47) ao afirmar que "ensinar não é transferir conhecimento, mas criar as possibilidades para a sua própria produção ou a sua construção". Isso aconteceu numa proposta que, embora pedagógica, é desprovida de regras ou manuais, uma vez que preza pelas manifestações artísticas teatrais de expressão privilegiada de imaginação, de criação e de interação com o livro, com a história contada.

Segundo Cosson (2009), é um equívoco pensar que os livros falam por si só, pois. no momento da leitura, há a necessidade de intervenção ou mediação, uma vez que o ato de ler não é solitário e deve ser compartilhado.

Infelizmente, ainda percebemos tal equívoco na prática docente, no entanto, compartilhamos do pensamento desse autor ao enfatizar que o letramento literário é indispensável se quisermos formar leitores capazes de vivenciar toda a força humanizadora da literatura e não apenas leitores que "leem bem".

Quanto ao exercício dramático, o jogo criativo e dinâmico aprimora habilidades que, segundo Vygotsky (1988), são inerentes à formação do ser humano, pois somos os únicos animais capazes de pensar sobre outros modos de agir, em lugares e tempos diferentes, sendo nossas primeiras experiências com a linguagem, no jogo ou através da imaginação. (COLOMER, 2003, p.88) 
Não há garantias nessa proposta, nem tampouco certezas. O que há é uma experiência feliz de um abraço literário das crianças com um livro interessante. Cada educador ou mediador de leitura pode tê-lo como um caminho possível à formação do gosto literário a ser pensado em sua realidade.

\section{Referências}

ALBUQUERQUE, Eliana Borges Correia de. Conceituando alfabetização $e$ letramento. In: Santos, Carmi Ferraz \& Mendonça, Márcia (org.). Alfabetização e letramento: conceitos e relações. 1.ed., 1.reimp. - Belo Horizonte: Autêntica, 2007.

CANDIDO, Antônio. O direito à Literatura. In: Vários escritos. Rio de Janeiro/São Paulo: Ouro sobre Azul/Duas Cidades, 2004. p.169-191.

COELHO, Nelly Novaes. Literatura infantil. São Paulo: Ed. Moderna, 2000.

COLOMER, Teresa. A formação do leitor literário. São Paulo: Global Editora, 2003. COLOMER, Teresa. Andar entre livros: a leitura literária na escola. Trad. Laura Sandroni. São Paulo: Global, 2007.

COSSON, Rildo. Letramento literário: teoria e prática. $4^{\mathrm{a}}$ ed. São Paulo: Contexto, 2014.

FREIRE, P. Pedagogia da Autonomia: saberes necessários à prática educativa. 35 ed. São Paulo: Paz e Terra, 2007. (Coleção Leitura)

GARCIA, Gabriel. Texto publicado no Volume 2 - Prazer em Ler. SP. 2007, publicação do Programa Prazer em Ler, do Instituto C \& A e CENPEC.

PAULINO, Graça; COSSON, Rildo. Letramento literário: para viver a literatura dentro e fora da escola. In: RÖSING, Tânia M. K.; ZILBERNAM, Regina (Orgs.). Escola e leitura: velha crise, novas alternativas. São Paulo: Global, 2009.

PRADO, Adélia. Texto publicado no Volume 2 - Prazer em Ler. SP. 2007, publicação do Programa Prazer em Ler, do Instituto C \& A e CENPEC.

SCLIAR, Moacyr J. O irmão que veio de longe. $2^{a}$ ed. São Paulo: Companhia das letras, 2006.

Bertrand Brasil, 2007.

O texto, ou: a vida - uma trajetória literária. Rio de Janeiro:

SOARES, Magda Becker. A escolarização da Literatura Infantil e Juvenil. In: de EVANGELISTA, Aracy, et al. (Orgs.). A Escolarização da Literatura: O Jogo do Livro Infantil e Juvenil. Belo Horizonte: Autêntica, 1999.

VIGOTSKY, Lev Semenovich; LURIA, Alexander Romanovich; LEONTIEV, Alexis N. Linguagem, desenvolvimento e aprendizagem. Tradução de Maria da Penha Villalobos. 2. ed. São Paulo: Ícone, 1988. p. 103-117. 
ZILBERMAN, Regina. Moacyr Scliar para crianças. Disponível em http://www.cartacapital.com.br/educacao/carta-fundamental-arquivo/moacyr-scliarpara-criancas. Último acesso em 20/05/2016.

Recebido em 07 de julho de 2018

Aceito em 04 de novembro de 2018 